\title{
An Electrochemical Study of the Corrosion Resistance of Niobium-Aluminum Carbonitride Coating Produced on Steels by Thermo-Reactive Diffusion Technique
}

\author{
E. Abakay*, M. Durmaz, S. Sen and U. Sen \\ Sakarya University, Engineering Faculty, Department of Metallurgical and Materials Engineering, \\ Esentepe Campus, 54187 Sakarya, Turkey

\begin{abstract}
Thermo-reactive diffusion/deposition technique is an alternative to physical vapor deposition and chemical vapor deposition techniques for obtaining wear and corrosion resistant coatings on steel parts. In this work, thermo-reactive diffusion/deposition technique was used to produce niobium aluminum carbonitride-based coatings on AISI M2 steel. Characterization of the coatings was done by X-ray diffraction analysis, scanning electron microscopy and energy dispersive spectroscopy. The corrosion resistance of the produced coatings was investigated by using potentiodynamic polarization in a solution of $0.5 \mathrm{M} \mathrm{NaCl}$. Hard, compact and adherent coatings, mainly consisting of $\mathrm{NbC}$ and $\mathrm{NbN}$ phases were obtained. The corrosion behavior of the samples was investigation by potentiodynamic polarization measurements.
\end{abstract}

DOI: 10.12693/APhysPolA.132.682

PACS/topics: 81.65.Lp, 81.65.Kn, 87.64.Ee

\section{Introduction}

Steel is one of the most used materials in industrial applications due to its high strength, high toughness, good machining ability, and low cost. With these attractive properties, steels are the most commonly used materials for the cutting tools, forming molds, punches, etc. The corrosion resistance of these parts is one of the important properties to consider besides the high hardness, thermal stability and wear resistance [1-3]. Coating of steel surfaces with non-oxide ceramic layers is an extensively studied technique for enhancement of the mentioned properties. The most commonly used techniques for coating of steel surfaces are physical vapor deposition, chemical vapor deposition, thermal spraying and plasma electrolytic oxidation [4-7].

Due to low cost and the requirement of only basic equipment, thermo-reactive diffusion/deposition (TRD) is an alternative method to the above-mentioned techniques. In this technique, carbon, nitrogen or boron from the substrate diffuse towards the deposited layer of transition metals ( $\mathrm{Nb}, \mathrm{Cr}, \mathrm{Ti}, \mathrm{Ti}$, etc.), and react with these elements in the layer. TRD process can be realized by (i) molten salt bath, (ii) fluidized bed and by (iii) pack method. In the pack method, a powder mixture which contains the reactive metals (a ferrous alloy or oxides of the metal), chloride or fluoride salts, like ammonium chloride, used as activators, alumina, used as filler material, and naphthalene, used as the deoxidizer, are employed. Detailed information about the TRD process and the pack method can be found in [8-12].

*corresponding author; e-mail: eabakay@sakarya.edu.tr
Niobium carbide and nitride coatings are good candidates for applications, where wear resistance and high hardness is important. Mechanical, microstructural and wear properties of coatings obtained by TRD method were investigated in detail [13-16]. Recently, the corrosion resistance of the TRD coatings has been a popular trend for the researchers. These studies were focused on the niobium, vanadium and chromium carbide coated samples. In literature there are also investigations of nitride-based coatings.

The aim of this study is to investigate the corrosion resistance of niobium aluminum carbonitride coatings, realized on AISI M2 steel, with variable aluminum content and aluminum free, by Tafel polarization method. Furthermore, microstructural properties and phase formation were also investigated, for a more detailed explanation, considering the conditions of use.

\section{Experimental details}

In the present work, a commonly used high-speed steel (HSS) AISI M2 was selected as the substrate. High-speed steels are widely known for their high hardness at elevated temperatures and are mainly used in cutting tools for steels or other metals and alloys in high-speed machining applications [17]. The substrate was supplied from Buhler, Germany in the form of a bar, $20 \mathrm{~mm}$ in diameter. Slices measuring approximately $5 \mathrm{~mm}$ in thickness were cut from the bar and their surfaces were ground up to 1200 grid with emery paper and ultrasonically cleaned in ethanol for 15 minutes.

Before the TRD treatment, the samples were nitrided for $12 \mathrm{~h}$, at $570^{\circ} \mathrm{C}$, for obtaining N-rich surfaces. The TRD process was carried out on the pre-nitrided samples, using commercial ferroniobium, ammonium chloride $\left(\mathrm{NH}_{4} \mathrm{Cl}\right)$, aluminum, alumina, 
and naphthalene at $1000{ }^{\circ} \mathrm{C}$ for $2 \mathrm{~h}$. After the coating process, samples were quenched in air.

XRD patterns of the samples in Bragg-Brentano $\theta-2 \theta$ geometry were realized with the help of a Rigaku diffractometer (Model D/MAX-B/2200/PC, Rigaku Co., Japan) using copper $\mathrm{Cu} \mathrm{K} \mathrm{K}_{\alpha}$ radiation, continuous scanning at a speed of $2^{\circ} / \mathrm{min}$ and scanning angles ranging from $20^{\circ}$ to $80^{\circ}$. Cross-sectional morphologies were examined using scanning electron microscopy (Model JEOL JSM-6060, FEI Co., Japan) coupled with energy dispersive X-ray spectroscopy (EDS) on the cross section of the metallographically prepared samples.

The corrosion behavior of the samples was investigated in a three-electrode test unit with a graphite counter electrode and a calomel electrode as the reference electrode, using a PCI4/750/ZRA potentiostat-galvanostat (Gamry Instrument) controlled by a computer, in the $0.5 \mathrm{M} \mathrm{NaCl}$ solution, $\mathrm{pH}$ value of which was 5.87 at $25^{\circ} \mathrm{C}$. The open circuit potential was measured after 60 min immersion of the tested samples with an active area of $0.28274 \mathrm{~cm}^{2}$ in the solution for potential stabilization. Potentiodynamic polarization measurements were made at a potential scan rate of $5 \mathrm{mV} / \mathrm{sec}$. The scanning range was set from -1 to $+1 \mathrm{~V}$. Corrosion potential $E_{\text {corr }}$, corrosion current $I_{\text {corr }}$, anodic Tafel slope $\beta_{a}$, cathodic Tafel slope $\beta_{c}$ were obtained from the results using Gamry Echem Analyst Software.

\section{Results and discussion}

Cross-sectional SEM micrograph and EDS spectrum of $\mathrm{Nb}-\mathrm{Al}-\mathrm{N}-\mathrm{C}$ coatings realized on AISI M2 steel can be seen in Fig. 1a and b, respectively. According to the

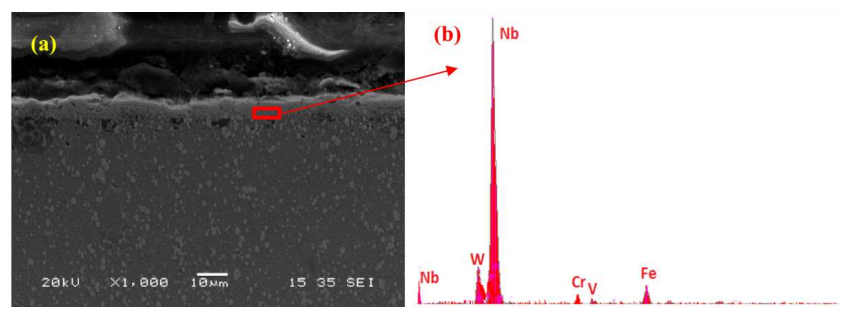

Fig. 1. (a) SEM micrograph and EDS analysis of NbAl-C-N coated AISI M2 steel.

SEM examination, a smooth and compact layer was formed on the substrate for all compositions. A transition zone with some porosity at the interface of the coating layer and the substrate was formed for all compositions. The porosity formation is generally observed under the coating layer after the thermochemical coating processes. Employment of pre-nitrided steels for TRD process can be the cause of the formation of porosity [10]. According to the EDS result, niobium was the dominant element in te layer. Tungsten, vanadium, chromium, and iron were also found in the coating layer. Elements other than niobium are the part of the substrate composition. The reaction of niobium with carbon and nitrogen from the steel substrate have caused niobium to become the dominant element in the coating layer.

Figure 2a shows the XRD patterns of the Nb-Al-C-N coated M2 steel. For all compositions, main phases in the structure are $\mathrm{Nb}_{6} \mathrm{C}_{5}$ and $\mathrm{NbN}$. In the TRD process, ferroniobium reacts with chlorine gas, which appears due to decomposition of ammonium chloride, and forms niobium chloride. Carbon and nitrogen diffusion occurs outwards from the steel sample and these interstitial atoms react with niobium chloride on the surface of the sample and form the $\mathrm{Nb}_{6} \mathrm{C}_{5}$ and $\mathrm{NbN}$ phases.
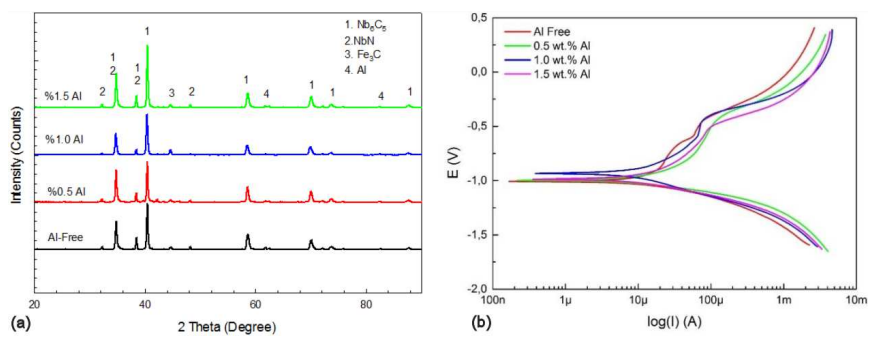

Fig. 2. (a) XRD patterns and (b) potentiodynamic polarization curves of Nb-Al-C-N coated AISI M2 steel.

For other coating techniques, the addition of aluminum to the structure is a popular method for increasing hardness and oxidation resistance $[18,19]$. In this work, the addition of aluminum has caused a change of peak intensities of the phases.

The results of potentiodynamic measurements of $\mathrm{Nb}$ Al-C-N coatings, with varied content of $\mathrm{Al}$, on the substrates of AISI M2 steel in the $0.5 \mathrm{M}$ aqueous sodium chloride solution are shown in Fig. $2 \mathrm{~b}$.

It is clear from a comparison (Table I) of the corrosion potential $E_{\text {corr }}$ of the Al-free Nb-C-N coated steel and $\mathrm{Nb}-\mathrm{C}-\mathrm{N}$ coatings realized with 0.5 wt.\%, 1.0 wt. $\%$ and 1.5 wt. $\%$ of $\mathrm{Al}$ included into the coating bath, that $E_{\text {corr }}$ has shifted to more positive potential values with the increase of $\mathrm{Al}$ content of the coatings, reaching $-1.010 \mathrm{~V}$ and $-0.978 \mathrm{~V}$ versus SCE. The increase of $E_{\text {corr }}$ indicates that increase of $\mathrm{Al}$ content in the coating bath causes the increase of the corrosion potential of the coatings. In addition, as shown in Fig. 2b, the increase in the $\mathrm{Al}$ content in the coating bath and thus, the increase of $\mathrm{Al}$ content in the coating layer, causes a decrease of the current densities through the coatings.

The corrosion current density is often used as an important parameter to evaluate the kinetics of corrosion reactions. Corrosion protection is normally proportional to the corrosion current density $i_{0}$ measured via polarization. In our case, the coatings are chemically not reactive, the corrosion current density indicates at pores in the coatings. The $i_{0}$ values from Fig. $2 \mathrm{~b}$ show that the $\mathrm{Nb}-\mathrm{Al}-\mathrm{C}-\mathrm{N}$ coating on the AISI M2 steel corroded faster than the Nb-C-N coating under open-circuit conditions. This means that the active area of the substrate due to coating porosity is higher in the case of $\mathrm{Nb}-\mathrm{Al}-\mathrm{C}-\mathrm{N}$ than in the case of Nb-C-N coatings. Therefore, the corrosion 
resistance of the coated samples that include aluminum has slightly decreased with the increase in aluminum content. However, the effect of aluminum on the corrosion behavior of Nb-C-N coatings is at negligible levels.

TABLE I

Potentiodynamic polarization data of the coated samples.

\begin{tabular}{c|c|c|c|c|c}
\hline \hline & $\begin{array}{c}\beta_{a} \\
{[\mathrm{mV} / \text { decade }]}\end{array}$ & $\begin{array}{c}\beta_{c} \\
{[\mathrm{mV} / \text { decade }]}\end{array}$ & $\begin{array}{c}I_{\text {corr }} \\
{[\mu \mathrm{A}]}\end{array}$ & $\begin{array}{c}E_{\text {corr }} \\
{[\mathrm{mV}]}\end{array}$ & $\begin{array}{c}R_{\mathrm{p}} \\
{[\Omega]}\end{array}$ \\
\hline Al-Free & 266.9 & 100.1 & 8.68 & -1010.0 & 3642 \\
0.5 wt.\% Al & 219.5 & 104.8 & 8.89 & -997.0 & 3465 \\
1.0 wt.\% Al & 501.1 & 295.5 & 17.30 & -993.0 & 4666 \\
1.5 wt.\% Al & 578.1 & 224.8 & 18.90 & -987.0 & 3719
\end{tabular}

\section{Conclusions}

Niobium aluminum carbonitride based coatings were obtained on AISI M2 steel using TRD technique with the addition of varied amount of aluminum. The coating layers were smooth, had compact topography and mostly included $\mathrm{Nb}_{6} \mathrm{C}_{5}$ and $\mathrm{NbN}$ phases. With increasing aluminum content, the corrosion rate of the coated samples showed an increase.

\section{References}

[1] H. Tavakoli, S.M. Mousavi Khoie, Mater. Chem. Phys. 124, 1134 (2010).

[2] S. Kirtay, Acta Phys. Pol. A 128, B-90 (2015).
[3] İ.H. Karahan, Acta Phys. Pol. A 130, 286 (2016).

[4] L. Shan, Y. Wang, Y. Zhang, Q. Zhang, Q. Xue, Wear 362-363, 97 (2016).

[5] L. Pezzato, K. Brunelli, P. Dolcet, M. Dabalŕ, Surf. Coat. Technol. 307, 73 (2016).

[6] S. Khara, S. Choudhary, S. Sangal, K. Mondal, Surf. Coat. Technol. 296, 203 (2016).

[7] J A. Günen, Acta Phys. Pol. A 130, 217 (2016).

[8] A. Ghadi, M. Soltanieh, H. Saghafian, Z.G. Yang, Surf. Coat. Technol. 289, 1 (2016).

[9] U. Sen, S.S. Pazarloglu, S. Sen, Mater. Lett. 62, 2444 (2008).

[10] M. Biesuz, V.M. Sglavo, Surf. Coat. Technol. 286, 319 (2016).

[11] T. Arai, Thermochemical Surface Engineering of Steels, Woodhead Publishing, Oxford 2015.

[12] S. Sen, Mater. Design 27, 85 (2006).

[13] S. Sen, K. Kocaman, J. Mater. Sci. 46, 7784 (2011).

[14] A. Orjuelag, R. Rincón, J.J. Olaya, Surf. Coat. Technol. 259, 667 (2014).

[15] C.K.N. Oliveira, R.M.M. Riofano, L.C. Casteletti, Surf. Coat. Technol. 200, 5140 (2006).

[16] U. Sen, Mater. Chem. Phys. 86, 189 (2004).

[17] S. Sackl, H. Leitner, H. Clemens, S. Primig, Mater. Characterization 120, 323 (2016).

[18] H.C. Barshilia, B. Deepthi, K.S. Rajam, K.P. Bhatti, S. Chaudhary, J. Mater. Res. 23, 1258 (2008).

[19] M. Hirai, Y. Ueno, T. Suzuki, W. Jiang, C. Grigoriu, K. Yatsui, Jpn. J. Appl. Phys. 40, 1056 (2001). 